\title{
CURRÍCULO, POLÍTICA E IDEOLOGIA: ESTUDOS CRÍTICOS NA EDUCAÇÃO SUPERIOR EM SAÚDE
}

\section{SYLLABUS, POLICY AND IDEOLOGY: CRITICAL STUDIES IN HIGHER EDUCATON IN HEALTH}

\author{
Gustavo de Oliveira Figueiredo ${ }^{1}$ iD (0000-0003-2724-8826), Yansy Aurora Delgado Orrillo ${ }^{1}$ iD (0000-0002-9367-9459)
}

\author{
${ }^{1}$ Universidade Federal do Rio de Janeiro, Instituto NUTES de Educação em Ciências e Saúde, Rio de \\ Janeiro, Brasil. <gfigueiredo.ufrj@gmail.com>
}

Resumo Este ensaio teve por objetivo analisar como ideologias e políticas públicas influenciam no currículo dos cursos de graduação em saúde. Discute-se a tecnificação do ensino superior, em que os cursos de graduação em saúde apresentam uma lógica especializada, fragmentada e produtivista do cuidado em saúde, e cujos currículos permitem a reprodução acrítica da visão de mundo hegemônica. Nesse caminho, constroem-se as identidades profissionais de sujeitos cujas representações sociais estão influenciadas pelo sistema de valores privados com ideias e prescrições que penetram na subjetividade dos educandos e educadores. Entretanto, na perspectiva dialética do processo educativo, a dominação não suprime a possibilidade de resistência, por isso é que se busca analisar alguns espaços de lutas contraideológicas, assim como discutir os desafios na construção de currículos que valorizem o diálogo sobre a realidade histórica de desigualdade no país e estimule a tomada de consciência crítica para a transformação social. Essa perspectiva permite a construção de um ambiente político mais plural e dinâmico em que se perceba a universidade como espaço de formação humana e cidadã abrangente, comprometida e coerente com o Sistema Único de Saúde.

Palavras-chave política; ideologia; currículo; educação superior; educação em saúde.
Abstract The objective of this essay was to analyze how ideologies and public policies influence the syllabus of undergraduate health courses. The technification of higher education is discussed, in which undergraduate courses in health present a specialized, fragmented and productivist logic of health care, and whose syllabi allow the uncritical reproduction of the hegemonic worldview. In this path we build the professional identities of individuals whose social representations are influenced by this system of values, ideas and prescriptions that penetrate the subjectivity of the students. However, as the educational process is dialectical and contradictory, domination does not suppress resistance; spaces of counter-ideological struggle are discussed in the article, as well as the challenges in building a syllabus that values students' knowledge and stimulates critical awareness for social transformation. This perspective would allow the construction of a more plural and dynamic political environment in which one can perceive the university as a more comprehensive, socially committed, and coherent formation space with the guidelines of the Brazilian Unified Health System. Keywords politics; ideology; syllabus; college education; health education. 


\section{Introdução}

Os estudos do currículo na educação superior em saúde formam um eixo de investigação no campo teórico do ensino, formação e educação em saúde. A análise desse eixo específico compreende os processos de formação universitária de profissionais de saúde, e este ensaio é um esforço refletir sobre o nível superior de ensino. Estamos, portanto, analisando o modo como as ideologias e as políticas se imbricam formando um amálgama no currículo dos cursos de graduação em saúde. Antes será preciso, entretanto, considerar alguns aspectos de cunho epistemológico.

$\mathrm{O}$ contexto histórico brasileiro no século XX foi marcado pelas ideologias desenvolvimentistas da modernidade e pelos conflitos gerados na tensão capitalismo/comunismo. Ainda que o processo de urbanização no Brasil tenha características próprias, seguiu um 'modelo' ou 'sistema' de produção que reforçou a desigualdade social e produziu as ideias que determinam as estruturas e os processos sociais atuais. Essa perspectiva histórica e dialética é adotada para se compreender o modo como o país atualmente se insere no modelo de globalização sustentado pela ideologia neoliberal.

A educação superior no Brasil foi historicamente marcada pela exclusão da maior parte da população, por meio da restrição do acesso ao nível superior e também por um currículo tradicional, marcado pelo poder concentrado no professor, pelo excesso de zelo pelos conteúdos, pelo predomínio de instrumentos de controle e disciplina e pela hegemonia do conhecimento técnico-científico. A adoção de uma perspectiva dialética permite compreender como o currículo influencia na cultura organizacional e nas relações interpessoais. Para se fazer a crítica de uma relação professor-aluno caracterizada pela ausência de diálogo, é preciso compreender como a ideologia capitalista difundiu um modelo tecnicista de formação universitária, isolando arbitrariamente educação e política para controlar o valor do saber.

\section{Relação dinâmica entre as categorias ideologia, política e educação}

Entendemos o conceito de ideologia com base em Marx e Engels (1965), quando a definem como um sistema ordenado de ideias ou representações de normas ou regras, como algo separado e independente das condições materiais, que surge quando há desvinculação da força produtiva de trabalho com o pensamento intelectual. Uma forma de controle e repressão, num domínio silencioso garantido pela alienação da história como fato social. Para os autores, a noção progressista da história forja uma estabilidade inexistente no sistema de relações sociais; omite o poder dos que produzem a matéria, evocando entidades totalizadoras para reger o mundo, como um mecanismo de representação da classe dominante. Assim, as ideias construídas pelo 
homem sobre o mundo deixam de ser meras interpretações para serem assumidas como verdades absolutas (Marx e Engels, 1965). Analisando por uma lente histórica, Schraiber (1989) afirma que a subordinação da educação ao modelo industrial ocorre no Brasil principalmente a partir dos anos $1940 \mathrm{e}$ impacta a formação dos profissionais de saúde, de modo que a especialização exacerbada se constituiu num mecanismo de alienação da realidade social. O desenvolvimento industrial alterou o padrão da qualificação do trabalho e exigiu novos requisitos do trabalhador. O discurso do progresso e da urbanização construiu as bases estruturais para a implantação de mais uma ideologia moderna, a de que o desenvolvimento do país exige a formação de técnicos especializados.

Essas transformações sociais impactam fortemente o desenvolvimento da educação superior no país, já que acaba por culminar em dois movimentos de reforma universitária - o primeiro, autoritário, em plena ditadura militar; e o segundo, hegemônico já nos primeiros anos de implantação do neoliberalismo no Brasil. Esse segundo movimento, por sua vez, teve seu apogeu no final dos anos 1980 como resposta às exigências de um modelo capitalista mais liberal que se instalava no Brasil. Dessa forma, a educação priorizou o conhecimento útil para a atuação específica num ofício, as informações técnicas foram supervalorizadas, estimulando a formação de uma reserva de trabalhadores treinados para o trabalho, mas com pouca consciência crítica da realidade do país e da sua inserção no modelo produtivo (Mendes, 1983).

De acordo com Ribeiro (1998), a principal face da ideologia no processo educativo é a tecnificação, tratando o conhecimento como um dado técnico, desprovido de outras mediações que não sua própria finalidade útil, e assim coisificado. A formação é substituída pela informação e pelo treino dos alunos, incorporando a disciplina e a alienação. Também ao analisar o processo de tecnificação da educação, Giroux (1986) afirma que a tendência do modelo econômico moderno é industrializar a mente, da mesma forma que o capitalismo industrializou a produção de bens durante sua ascensão. O pensamento humano com isso se torna mecanizado, e a mente corresponde a uma máquina - um instrumento tecnicizado, segmentado e degradado, que perdeu sua capacidade para o pensamento crítico; especialmente sua capacidade de imaginar outro modo de vida. Essa percepção certamente tem origem nas ideias de Marx (1971, p. 38), quando ele afirma que:

A especialização de manejar uma ferramenta parcial, uma vida inteira, se transforma na especialização de servir sempre a uma máquina parcial. (...) A habilidade especializada e restrita do trabalhador individual, despojado, que lida com a máquina, desaparece como uma quantidade infinitesimal diante da ciência, das imensas forças naturais e da massa de trabalho social, incorporadas ao sistema de máquinas e formando com ele o poder do patrão. 
O modo de produção capitalista, ao aplicar modos tayloristas e fordistas de organização do processo de trabalho, acaba por influenciar os currículos, que passam a priorizar a especialidade das disciplinas biomédicas em detrimento da formação social e humana dos profissionais. Os cursos promovem poucas atividades interdisciplinares e não preparam adequadamente os profissionais para o trabalho em equipe. Assim, espera-se que esse corpo profissional atue de modo integrado para a estruturação do sistema. Contudo, o próprio processo de formação é isolado em cursos que pouco dialogam entre si. Cada curso tem suas ideologias e objetivos, o que acaba por produzir barreiras na interação e na proposição de novas estruturas do trabalho em saúde. A situação é de tal forma complexa e desfavorável à sociedade que Botazzo (2000) denuncia que o ensino de graduação em saúde ministrado não está formando o produto que a população necessita, uma vez que esses profissionais são formados com um currículo essencialmente tecnicista, caracterizando-se principalmente por uma ênfase maior no curativo, em detrimento da atividade política necessária à promoção de saúde.

Ao analisar exatamente essa relação entre pessoas e coisas, Kosik (1976, p. 201) afirma: “Na economia capitalista, verifica-se 'a personificação das coisas e a coisificação das pessoas'. Às coisas se atribuem vontade e consciência. A vontade e a consciência dos homens são determinadas pelo movimento das coisas." Para compreender bem essa relação invertida, recorremos novamente a Marx (1971), quando ele aprofunda o nível da análise e afirma que os produtos do cérebro humano parecem dotados de vida própria ao se constituírem como figuras autônomas que mantêm relações entre si e com os seres humanos. Ou seja, é exatamente o que ocorre com os produtos da mão humana no mundo das mercadorias. A esse fenômeno o autor denomina de 'fetichismo', e explica que ele decorre do caráter social próprio do trabalho que produz mercadorias.

Como fruto dessa história de subserviência da educação ao modelo produtivo capitalista, Figueiredo, Brito e Botazzo (2003) afirmam que o ensino superior no país é, como regra, de caráter fortemente conservador, alienado da política e desengajado das lutas sociais. Segundo os autores, as críticas que se fazem ao modelo de educação em saúde vigente refletem uma preocupação em se redimensionar o padrão clássico das intervenções educativas e das práticas de saúde, com suas tendências tradicionais à manutenção de modelos autoritários e tecnicistas na educação superior.

O modelo como o Brasil historicamente se insere no processo de globalização é contraditório. Ao mesmo tempo que há uma adequação do país às regras do Fundo Monetário Internacional, ${ }^{1}$ existe uma necessidade cada vez maior de programas sociais eficazes que consigam diminuir as diferenças sociais e atendam minimamente às necessidades da população. Ao analisar a função da universidade na discussão sobre o modelo de inserção do país na economia mundial, Tavares (1997, p. 17) constata: 
Todas as formas de acumulação de capital inventadas neste país são desequalizadoras. Não é só o estatuto colonial, a origem escravista que produz essa cultura miserável dos senhorios. O problema é do modelo de acumulação, é a modalidade de inserção do país no capitalismo, que sempre foi dinâmica, mas excludente. (...) a universidade vai muito mal. É uma absoluta ausência de debates. Os movimentos sociais ficam com toda a responsabilidade, como se nós, os intelectuais, não tivéssemos nada a ver com isso.

Como destaca a autora, papel fundamental no processo educativo têm os intelectuais, e é preciso considerar que nesse contexto de influências a maioria dos docentes também realiza pesquisas científicas e colabora na construção do ambiente de ideias que circula em determinada instituição de ensino. Também Giroux (1986) considera que os professores são intelectuais e atribui-lhes suma relevância no processo de manutenção ou transformação da realidade presente.

De acordo com Gruppi (1978), no pensamento de Gramsci os intelectuais são os 'persuasores' da classe dominante; são eles que elaboram as ideologias, são os 'funcionários da hegemonia da classe dominante'. Os intelectuais não são um grupo social autônomo, mas cada grupo social, afirmando uma função específica na produção econômica, forma intelectuais que se tornam os técnicos da produção. Esses intelectuais não se limitam a ser apenas os técnicos da produção, mas também emprestam à classe economicamente dominante a consciência de si mesma e de sua própria função, tanto no campo social quanto no campo político. Ainda para o mesmo autor, o capitalismo industrial cria essencialmente os técnicos e os cientistas, ligados à produção. Estes são considerados como os intelectuais orgânicos ao capitalismo.

Para Demo (1998), ideologia mais potente é a que se traveste de ciência. Por isso, seu arquiteto típico é o intelectual, figura importante na justificação do poder, como também na elaboração da contraideologia, visando mudar a história dominante. Reforçando o discurso contraideológico, Touraine (1997) afirma que o papel do intelectual deveria ser o de ajudar na emergência do sujeito, aumentando a vontade e a capacidade dos indivíduos de serem atores de sua própria vida. Aqui, o sujeito se choca com a lógica dominante do sistema, que o reduz ao papel de consumidor e de defensor de seus interesses em um ambiente mutável; ele está igualmente ameaçado pela fuga para fora do campo social e de sua diversidade, para a homogeneidade fictícia de uma tradição comunitária ou para uma fé religiosa. Os intelectuais têm por tarefa principal construir a aliança entre o sujeito e a razão, entre a liberdade e a justiça.

Portanto, é importante ressaltar que existem mediações e ações no nível das instituições de ensino e do currículo que podem trabalhar contra os desígnios do poder e do controle. A vida social, assim como o currículo, não é feita apenas de dominação e controle; há espaço para a oposição e a resistência, para a rebelião e a subversão. O currículo é, em suma, um território 
político. É imprescindível que fique explícita, portanto, a existência de dois currículos: o primeiro é o currículo formal, aquele que é protocolado, está escrito em algum papel, é lei, seus objetivos ficam, ao menos teoricamente, explícitos; o outro currículo é oculto, e este, de acordo com Giroux (1986), é composto por normas, valores e crenças imbricadas e transmitidas aos alunos mediante normas subjacentes, que estruturam as rotinas e relações no espaço da escola e na vida da sala de aula.

\section{Reflexões sobre o currículo na educação superior em saúde}

Com o processo de globalização proporcionando uma internacionalização da produção, a formação de empresas transnacionais, as novas tecnologias de comunicação e informação, a revolução da internet e da microeletrônica e a hegemonia política da ideologia neoliberal, cresce a exigência de técnicos cada vez mais capacitados. É nesse contexto que são elaboradas as diretrizes curriculares nacionais.

Em novembro de 2001, visando cumprir a nova Lei de Diretrizes e Bases da Educação (LDB), ${ }^{2}$ que trata também da reforma do ensino superior no Brasil, o Ministério da Educação (MEC) aprovou, por meio do Conselho Nacional de Educação, o parecer que trata das diretrizes curriculares nacionais dos cursos de graduação em saúde. ${ }^{3}$ De acordo com Alves e Villardi (1997), a nova LDB garantiu às universidades o exercício da sua autonomia didático-científica na elaboração de seus próprios currículos, fundamentados em diretrizes estabelecidas. As diretrizes curriculares do MEC constituíram-se no principal documento orientador da reforma curricular exigida das instituições de ensino superior. Nesse documento, foi estabelecido o perfil desejável dos formandos egressos da área da saúde.

Profissional com formação generalista, humanista, crítica e reflexiva, para atuar em todos os níveis de atenção à saúde, com base no rigor técnico e científico. Capacitado ao exercício de atividades referentes à saúde da população, pautado em princípios éticos, legais e na compreensão da realidade social, cultural e econômica do seu meio, dirigindo sua atuação para a transformação da realidade em benefício da sociedade (Brasil, 2001, p. 9).

De acordo com essas diretrizes, o currículo de graduação do profissional de saúde deve contemplar o sistema de saúde vigente no país, a atenção integral da saúde num sistema regionalizado e hierarquizado de referência e contrarreferência e o trabalho em equipe. Segundo o documento, os conteúdos essenciais para o curso de graduação devem estar relacionados com todo o processo saúde-doença do cidadão, da família e da comunidade e integrado à realidade epidemiológica e profissional. Entretanto, para Paim e Almeida Filho 
(2000), a revisão e o desenvolvimento curricular podem ser medidas necessárias para a reatualização das instituições de ensino, em face da reorganização das práticas de saúde, porém insuficientes para alterar o modo de produção. Os autores afirmam que a difusão de ideologias modernizantes e inovações curriculares tem sido insuficiente para promover alterações significativas na formação de profissionais da saúde.

Também Silva (1999) amplia a compreensão critica desse movimento de reforma, quando nos recorda que o currículo está estritamente relacionado às estruturas econômicas e sociais mais amplas. Portanto, não é um corpo neutro, inocente e desinteressado de conhecimentos. A seleção que constitui o currículo é o resultado de um processo que reflete os interesses particulares de classes e grupos dominantes. Ainda de acordo com o autor, algumas questões devem ser propostas: “Quais interesses guiaram a seleção desse conhecimento particular? Quais as relações de poder envolvidas no processo de seleção que resultou nesse currículo particular?" (Silva, 1999, p. 16).

Na discussão sobre o currículo, é importante ressaltar que todos os aspectos do ambiente escolar que, sem fazer parte do currículo oficial explícito, contribuem, de forma implícita, para aprendizagens sociais relevantes constituem, de acordo com Silva (1999), o currículo oculto. Nessa perspectiva, o que se aprende no currículo oculto são fundamentalmente atitudes, comportamentos, valores e orientações que permitem um ajuste dos indivíduos às estruturas hegemônicas. Ensinam-se, em geral, o conformismo, a obediência e o individualismo, por meio de rituais, regras, regulamentos e normas implícitas. Os professores são modelos, e da mesma forma o seu discurso, que influencia na formação da identidade pessoal e particularmente, de forma mais acentuada, na identidade profissional de seus alunos, por meio de mecanismos de identificação positiva ou negativa, transferindo valores e visões de mundo repletos de ideologias (Figueiredo, 2002).

A educação formal, no papel da escola e dos professores, transmite os modelos de comportamento que prevalecem numa sociedade. Essa reprodução, entretanto, não é um evento isolado da cultura, da política nem da economia. Ao contrário, é exatamente a cultura de um país - e a resultante das forças políticas em disputa - que irão determinar o grau de subordinação das políticas educacionais à estrutura econômica e produtiva de um país. A reprodução das ideias e das formas de relação interpessoal que se estabelece entre sujeitos, grupos ou classes é determinada por meio de sistemas de pensamento que muitas vezes se incorporam ao discurso dos professores de forma imperceptível, num mecanismo de reprodução ideológica e de dominação, restringindo o seu potencial transformador. O conceito de habitus, proposto por Bourdieu (1994), representa muito explicitamente o mecanismo de funcionamento da reprodução acrítica da visão de mundo hegemônica predominante na maioria das instituições de ensino do país: 
[… são sistemas de disposições duráveis, estruturadas, predispostas a funcionar como estruturas estruturantes, isto é, como princípio gerador e estruturador das práticas e das representações que podem ser objetivamente 'reguladas' e 'regulares' sem ser o produto da obediência a regras, objetivamente adaptadas a seu fim sem supor a intenção consciente dos fins e o domínio expresso das operações necessárias para atingi-los e coletivamente orquestradas, sem ser o produto da ação organizadora de um regente (Bourdieu, 1994, p. 61).

Especificamente no campo da saúde, existem dois aspectos a serem considerados. Se de um lado o habitus e a ideologia dominante no mercado são a produção de espaços privados de cuidado e, com isso, a obtenção de lucros individuais, de outro, especificamente no campo acadêmico, existe uma forte contraideologia que foca na produção de conhecimento de um Sistema Único de Saúde (SUS) público, universal e mais equânime. Mas de que modo o confronto dessas ideologias interagem no processo de formação em saúde?

Portanto, é compreensível que o relatório final da X Conferência Nacional de Saúde (Brasil, 1998) tenha sugerido que o Conselho Nacional de Saúde e o Ministério da Saúde devessem coordenar, junto com o Ministério da Educação, os conselhos profissionais da área da saúde e as instituições de ensino superior (públicas e privadas), os processos de reforma curricular com o objetivo de preparar os profissionais para trabalhar no SUS. Entretanto, se a visão de mundo daqueles que estão no cotidiano da formação - ou seja, os professores, no dia a dia das salas de aula - não apoiar essa discussão, as reformas curriculares terão um poder de transformação quase nulo, já que se atuaria exclusivamente no currículo formal, desconsiderando que é nas relações interpessoais que se constroem conhecimentos, pensamentos ou se transmitem ideologias.

Com base no princípio de que o currículo é um campo social em que se trava uma luta em torno de valores, significados e propósitos sociais, é fácil compreender o que aponta Giroux (1986) quando afirma que, subjacente à lógica do currículo, está um silêncio estruturado a respeito da relação entre classe social e cultura. Para o autor, embora as escolas sejam espaços culturais marcados por relações complexas de dominação e resistência, o discurso oficial da escola despolitiza a noção de cultura e descarta a resistência, ou pelo menos a sua significação política.

Num esforço de construir essa resistência, surgem propostas para um currículo crítico na educação superior em saúde. Paim (1994) afirma que nessa perspectiva crítica o currículo não decorreria de uma deposição tradicional de conteúdos ou disciplinas, mas de uma prática educativa centrada em um tripé que contempla análises de situações concretas, produção científica e reflexão teórico-epistemológica. Apesar do tripé proposto pelo autor, talvez para que a área da saúde possa efetivamente formar profissionais críticos e comprometi- 
dos com a realidade social da população brasileira, seja necessária ainda uma discussão mais elaborada sobre a política cotidiana. Para isso, certamente é necessário decodificar e compreender os significados dos elementos do currículo oculto e as disputas por sentido da formação no interior de cada universidade.

Ao fazer também uma crítica consistente à insuficiência das reformas curriculares isoladamente para a transformação da educação superior em saúde, Schraiber (1989), numa análise específica sobre a formação médica, afirma que será na esfera do trabalho e da organização social dos serviços que ocorrerão as transformações. A autora destaca ainda que há fortes barreiras políticas e econômicas para a reorganização direta da produção e distribuição dos serviços médicos. Segundo ela, o problema que tem acontecido de fato é que as propostas para a transformação das situações de prática profissional terminam sendo reformas curriculares, alianças do ensino escolar com a realidade dos serviços da rede assistencial comum ou novas metodologias didáticas de motivação e reorientação do interesse do aluno - ações com poder de transformação muito restrito.

Ao reforçar essa perspectiva crítica, Pires (1998) afirma que a inadequação entre o currículo de formação dos profissionais de saúde e as expectativas da sociedade vão além da questão de redefinição de um perfil profissional. Segundo a autora, a solução não está exatamente no perfil do egresso, mas na concepção que se tem a respeito do que seja currículo e do papel que se atribui à escola. Numa certa perspectiva, a escola pode ser pensada como uma mera transmissora de saberes neutros, isto é, de valores incontestáveis, sem referência a seus contextos de produção ou de aplicação. Saberes cristalizados, anteriores à experiência, acima e à parte das relações sociais. Nessa ótica, a escola não é vista como campo de construção e reelaboração crítica da formação humana, mas como um local de consumo de conhecimentos úteis para o trabalho, produzidos fora dela, e sobre os quais ela não tem responsabilidades éticas ou morais.

Como consequência desse currículo hegemônico na educação superior em saúde, podemos observar que uma característica comum entre os profissionais dessa área é a dificuldade de se enquadrar na equipe e, ainda, na sociedade como cidadão. Essa não relação entre os profissionais e a sociedade é criada ainda nos cursos de graduação, quando as disciplinas são cursadas isoladamente e existem poucas atividades que valorizam a vivência interdisciplinar e interpessoal. De acordo com Figueiredo, Brito e Botazzo (2003), raramente há dentro da universidade um estímulo a essa troca de saberes e à integração entre as áreas. Esse é um dos problemas que denunciam a grave deficiência nos currículos de formação. O ensino técnico é valorizado em detrimento do ensino crítico, político e humanizado, com foco exacerbado nas atividades técnicas, mas não nas reflexões que poderiam ser desenvolvidas com base em conhecimentos das ciências sociais e humanas. 
Para compreender melhor esse processo, é necessário que nos reportemos ao percurso dos estudantes na universidade. Ao ingressar na faculdade para a formação superior na área da saúde, esses jovens se deparam com as disciplinas do ciclo básico, em que o ensino privilegia a memorização. Durante a formação acadêmica, a carência de projetos de extensão que promovam o estímulo dos alunos às práticas sociais, os quais priorizam o contato com a comunidade, é tão grande que se forma um 'abismo', causando no aluno certo desinteresse do compromisso social. As disciplinas biomédicas, assim como as humanas, são quase sempre ministradas com total ausência de problematização. Os alunos aguardam ansiosamente para compreender a relação das disciplinas do básico com a clínica e na maioria das vezes não são estimulados a exercitar o seu senso crítico; acreditam fielmente na instituição pela qual optaram. Segundo Thiollent (1979), frequentemente observam-se comportamentos ostentatórios por parte do professor, que elabora o programa mais em função do brilho de sua formação e do prestígio da bibliografia do que de qualquer critério didático.

No ciclo profissional, os estágios extracurriculares são procurados pelos estudantes em sua busca por aprimoramento técnico. Quando iniciam os estágios em serviços de saúde, hospitais ou ambulatórios, os alunos passam a conviver mais de perto com a realidade dos serviços de saúde. Esse contato com a realidade pode se dar de forma egoísta, tirando o máximo de proveito e adquirindo o máximo de conhecimento numa relação de dominação e exploração da patologia e manipulação do corpo do paciente, ou pode também se dar de forma orientada e assim ir problematizando a realidade e aprendendo atitudes de respeito à diversidade humana. Para Bruno (1994), é uma característica dos cursos da área da saúde que os alunos realizem monitorias nas disciplinas com as quais se identificam. Com isso, vão se delineando os perfis profissionais e sendo realizadas opções precoces pela área de especialização.

Também como especificidade no campo da educação superior em saúde, Figueiredo, Brito e Botazzo (2003) afirmam que os últimos períodos são preenchidos basicamente com atividades clínicas e que, na clínica, os procedimentos valem pontos em muitas disciplinas. Como salientam os autores, a prioridade nem sempre é dada à real necessidade do paciente, mas muitas vezes o olho treinado em diagnosticar patologias não consegue enxergar integralmente o sujeito - ainda que, por menor espaço que se possa dar à fala do paciente e dedicação de tempo a escutar suas necessidades de saúde, a clínica nunca possa se desvincular da comunicação, das relações interpessoais e da intersubjetividade que se constroem na corresponsabildade pelo cuidado na atenção à saúde. Muitas vezes não há tempo de conversar com o paciente, nem com os colegas, tampouco com os professores. Frequentemente, o único diálogo que se estabelece na clínica é a relação profissional de saúde-sujeito necessitado de atenção, com pouco suporte e muitas vezes sem nenhuma supervisão. 
Em trabalho realizado por Pretto (1989), alunos de graduação da área da saúde foram entrevistados e afirmaram que a formação é fundamentalmente técnica, pouco voltada para a prevenção e para o social; ensina a doença ligada ao rendimento econômico que se poder obter dela. Esse relato de estudantes é muito preocupante, se confrontarmos com as ideias progressistas de Chauí (1994), quando a autora afirma que enquanto não houver um conhecimento da história real, enquanto a teoria não mostrar o significado da prática imediata dos homens, enquanto a experiência comum de vida for mantida sem crítica e sem pensamento, a ideologia de dominação se manterá.

De acordo com dados do Instituto Nacional de Estudos e Pesquisas Educacionais Anísio Teixeira (Brasil, 2000), 42\% dos formandos da área da saúde relataram pouco ou nenhum interesse por saúde coletiva, enquanto $80 \%$ dos entrevistados tinham forte interesse por disciplinas cirúrgicas. Essa é a realidade também constatada por Ribeiro (2000), quando demonstra que os alunos de graduação, em sua maioria, continuam saindo da faculdade direcionados a fazer cursos de especialização para atuar apenas na doença já instalada. Quanto a esse aspecto, Portillo e Belaciano (1994) lembram que a especialização profissional não é natural como aparenta ser, mas um processo social, resultado decorrente da divisão técnica e social do trabalho. No caso da formação em saúde, os docentes são, em geral, profissionais que atuam em determinado sistema e não necessariamente possuem formação na docência. Existe, com isso, uma reprodução de valores e práticas que, culturalmente, constroem esses sujeitos.

Assim, ainda que não atue de forma homogênea, pelos e sobre os sujeitos, a universidade acaba por funcionar como uma máquina que reproduz o modelo de produção em série. Esse modelo hegemônico espelha os valores culturais das elites, formando especialistas quase sempre incapazes de perceber as dicotomias do mundo e desinteressados pelo modo como a política atua no cotidiano. De acordo com Bourdieu (1987), os indivíduos programados, quer dizer, dotados de um programa homogêneo de percepção, de pensamento e de ação, constituem o produto mais específico de um sistema de ensino. Esse é o sistema de produção em série tal qual hegemonicamente se estrutura hoje também na educação superior em saúde.

\section{Mecanismos de identificação e construção da identidade profissional}

A identidade profissional é resultante da interação entre diversos fatores que atuam sobre o sujeito: seu grupo socioeconômico, seus valores pessoais, suas experiências prévias, assim como os sistemas ideológicos diversos que o ambiente universitário e o profissional proporcionam. Da visão de mundo fazem parte as experiências, a cultura, a formação profissional, a origem socioeconômica, a religiosidade, o gênero, a sexualidade, o ambiente familiar e a determinação política - ou seja, sistemas de valores eleitos pelos indivíduos, 
que são adotados e que determinam as suas atitudes. A eleição e a adoção de valores dependem do indivíduo, num processo de identificação pessoal, assim como da sociedade em que vive, das condições impostas pelo tempo e pelo contexto histórico. O encontro e a união com os pares, pessoas que compartilhem ideias e ideais semelhantes, caracterizarão o grupo e suas posições ante os fenômenos ideológicos (Guimarães, 1999).

Ao relacionar o conceito de visão de mundo ao de representação social, Minayo (1995) afirma que as representações sociais se manifestam em palavras, sentimentos e condutas e se institucionalizam. Portanto, devem ser analisadas com base na compreensão das estruturas e dos comportamentos sociais. De acordo com a autora, por serem ao mesmo tempo ilusórias, contraditórias e 'verdadeiras', as representações podem ser consideradas matéria-prima para a análise do social e também para a ação político-pedagógica de transformação, pois retratam e refratam a realidade segundo determinado segmento da sociedade.

Garrafa e Moysés (1996) oferecem um bom exemplo da influência que a indústria da saúde tem no imaginário dos estudantes. Com base em uma análise na área de odontologia, os autores esclarecem bem as atitudes corporativas ao revelar que, na organização dos congressos e reuniões científicas da categoria, os espaços de discussão e reflexão são ocupados quase que exclusivamente com demonstrações sobre fetichismo de novos materiais, medicamentos, aparelhos e técnicas que possam supostamente render mais lucros aos participantes desses eventos. Para os autores, “apesar dos discursos de preocupação e algumas medidas isoladas, muitas associações recebem forte apoio de grandes laboratórios farmacêuticos e outras poderosas empresas do setor para o patrocínio de megacongressos especializados" (Garrafa e Moysés, 1996, p. 12).

Uma ilustração desta constatação pode ser observada na entrevista com a coordenação de um congresso internacional de odontologia realizado em Goiás, publicada pelo jornal do Sindicato dos Odontologistas de Goiás (Soego): “Neste Congresso nós teremos uma odontologia ao vivo, onde serão executados procedimentos odontológicos num ambiente cuidadosamente preparado e transmitido em telões para uma sala. Nós teremos sete edições de odontologia ao vivo" (Soego, 2000, p. 7).

Com esse exemplo, podemos perceber como o fetiche tecnológico assume agora a versão de um reality show em que as mercadorias literalmente tomam vida própria. É possível observar o funcionamento do mais novo material da indústria e até fazer um test drive. Todo esse aparato de marketing da indústria influencia ideologicamente a construção das representações sociais que as profissões na área da saúde adquirem em cada cultura. Ao assumirem uma postura crítica diante desses processos de mercantilização da saúde a partir do campo da bioética, Berlinguer e Garrafa (1993) afirmam que as posições individuais e das próprias entidades científicas especializadas vêm lenta e gradualmente se modificando com relação ao comércio de partes do corpo humano. 
Manifestações, que eram inicialmente claras e categóricas, passaram a receber um tratamento cada vez mais brando e inconclusivo. A clareza foi sendo lentamente substituída pela dubiedade. Atualmente já são significativos, no contexto internacional, os setores existentes dentro da medicina e outros campos afins que defendem francamente a implantação de diferentes formas de compra e venda de tecidos e órgãos para atender à demanda clínica (Berlinguer e Garrafa, 1993, p. 326).

As universidades são formadas, em sua maioria, por professores que por serem considerados bem sucedidos na clínica privada, passam a ser símbolos de sucesso e prosperidade. Entretanto, ao comentar o autoritarismo e a onipotência existente entre os médicos e o modo como esse comportamento gera um estado de submissão nos pacientes, Quadra (1980) alerta para o fato de que, na verdade, esse comportamento é oriundo das relações violentas e excludentes que predominam na própria sociedade.

A educação superior na maioria dos cursos da área da saúde continua com a ilusão de uma certa neutralidade diante da política e da realidade social do país, quando na verdade é reprodutora da ideologia dominante. As instituições e os sujeitos reproduzem por meio do processo educativo todo um sistema de valores, ideias e prescrições que não são necessariamente explicitados formalmente, mas penetram profundamente na subjetividade de educandos e educadores. Como as divergências são raras, o modelo é sustentado.

A sustentação do modelo na sociedade não se mantém somente por meio do poder ou da propriedade, mas também, como afirma Williams (1997), inevitavelmente pela cultura do vivido. Esta última é considerada pelo autor como aquela saturação do hábito, da experiência, dos modos de ver, sendo continuamente renovada em todas as etapas da vida, desde a infância, sob pressões definidas e no interior de significados definidos, de tal forma que o que as pessoas vêm a pensar e a sentir é em larga medida a reprodução de uma ordem social profundamente arraigada, a que elas podem até achar que de algum modo se opõem - e a que, muitas vezes, se opõem de fato. Ainda segundo o autor, há um trabalho muito importante a ser feito em relação aos próprios processos de hegemonia cultural. As pessoas mudam, é verdade, por meio da luta e da ação (Williams, 1997).

\section{“Mas há resistências... E daí vêm as lutas!"4}

O sistema político, social e cultural, em nosso caso representado pelas universidades, reflete as contradições que surgem das relações sociais e econômicas que o país estabelece no processo de globalização. Exatamente com o propósito de revelar tais contradições é que Severino (1986) chama a atenção para o fato de que o resultado da educação brasileira não foi apenas a manutenção, a sustentação e a reprodução das condições econômico-sociais adversas 
da sociedade classista brasileira e da ideologia dos segmentos dominantes. No interior de seu próprio processo, dirigido no sentido da elaboração de um discurso ideológico com vistas à reprodução das condições sociais, o sistema educacional também provoca resultados não diretamente esperados e pode favorecer o desenvolvimento de um discurso contraideológico. Esse discurso contraideológico é também valorizado por Ricoeur (1983), quando destaca a importância da crítica à ideologia no processo de emancipação.

Nessa perspectiva, a dominação não elimina a ação humana de contestação nem a resistência, uma vez que o sujeito constituinte simplesmente não pode ser reduzido aos ditames do modo de produção da vida material, à lógica da dominação ou às agências de reprodução social. Segundo Giroux (1986), o processo educativo é dialético e contraditório, e exatamente por esse motivo abre espaço para discursos distintos, antagônicos, ideológico-mantenedores do status quo, ou um esforço contra a inércia, com um discurso contra a ideologia predominante.

Desse modo, também é preciso considerar em nossa análise que tal modelo de educação em saúde, hegemônico no país, recebe numerosas críticas e estimula ainda a construção de propostas alternativas. Num sentido inovador, a pretensão seria buscar um afastamento do tecnicismo dominante no ensino universitário em direção a um reconhecimento e valorização do saber do aluno; ao atendimento de suas expectativas e da sociedade; ao estímulo à crítica e à reflexão - além da valorização do conhecimento do universo cultural dos educandos. De acordo com Figueiredo, Brito e Botazzo (2003), numa abordagem desse tipo a educação deixaria de ser um processo de persuasão ou transferência unilateral de informação e passaria a ser um processo de diálogo, com a capacitação de indivíduos e grupos para a transformação da realidade. Além das técnicas, é necessário estimular uma prática social que contribua para a construção e o desenvolvimento da consciência crítica a respeito dos problemas que acometem hoje a sociedade brasileira, estimulando a busca de soluções e a organização para a ação coletiva e as reivindicações sociais. A universidade, assim, não seria apenas um espaço para formação técnico-científica, mas também, como afirma Tavares (1997), um espaço para se pensar a vida.

Uma ambição mais ousada seria o projeto descrito por Marcuse (apud Loureiro, 1999), em que as necessidades, os desejos e as aspirações deixariam de ser regidos pelos interesses privados que visam ao domínio e à perpetuação das formas destruidoras de relação do homem com a natureza. Ainda para o autor, uma sociedade livre requer a ruptura do vínculo estabelecido entre técnica e dominação de tal modo que "se houvesse uma mudança na direção do progresso que rompesse o vínculo entre a racionalidade da técnica e da exploração, haveria igualmente uma mudança na estrutura mesma da ciência - no projeto científico" (Loureiro, 1999, p. 52). Dessa forma, poderia o projeto científico ser um projeto de emancipação social, que significa “a 
libertação da natureza interna e externa do homem e, por conseguinte, uma relação não exploradora, mas fraterna e solidária com a natureza e com outros homens. Isto não significa retornar a uma pobreza sadia, à pureza moral, à simplicidade" (Loureiro, 1999, p. 53).

Ao reconhecer que o próprio processo educativo é ideológico, Freire (1997, p. 22) exprime seus desejos pessoais e cautelas tomadas para não reproduzir a ordem hegemônica: "Para me resguardar das artimanhas da ideologia, não posso, nem devo, me fechar aos outros. Nem tampouco me enclausurar no ciclo de minha verdade." E sugere um caminho para a tomada de consciência crítica: "o melhor caminho é recusar posições dogmáticas, em que o professor se afirma de forma autoritária como proprietário de uma verdade única". Do mesmo modo, para Zanetti (1998) o homem é um ser político, quer queira, quer não. Portanto, não existe homem neutro; ele pode, no máximo, ser neutralizado.

Matos (2000), ao reforçar o papel da resistência, acredita que em outro patamar estão os professores preocupados com o excesso do tecnicismo que envolve as profissões de saúde; sensibilizados pela falta de conteúdos ou disciplinas que trabalhem o lado humanístico, buscam encaminhar os alunos para o aprendizado não apenas de conteúdos cognitivos e psicomotores, mas também daqueles relacionados ao domínio emocional e político. Para a autora, quando desenvolvemos nosso trabalho com a compreensão da natureza histórica e política dos processos de adoecimento, certamente estamos um pouco mais preparados para enfrentar os atuais desafios da profissão: "teremos um senso crítico mais apurado, uma maior capacidade de abstração diante dos dogmas criados tanto na profissão como nos serviços" (Matos, 2000, p. 4).

Ao analisar a formação superior em saúde, Figueiredo, Brito e Botazzo (2003) afirmam que é um desafio construir um currículo crítico nas graduações diante da realidade atual da formação profissional, integrando o desenvolvimento de habilidades técnicas à percepção do universo social e da subjetividade de cada pessoa, alcançando uma formação capaz de satisfazer as necessidades individuais e também sociais, melhorando a atitude no atendimento clínico especializado, assim como a qualidade de vida da população. No mesmo sentido, é também um desafio construir um currículo integrado ao sistema de saúde, em que o aluno possa conhecer também os problemas da profissão e ter consciência crítica de sua formação acadêmica e da realidade em que se encontra a sociedade. Ainda de acordo com os autores, não se trata de inserir acadêmicos no SUS como mão de obra barata, mas proporcionar uma vivência prática dos serviços de saúde e da relação profissional-paciente e de ambos com a comunidade. Para isso se faz necessário fomentar uma discussão não só sobre o contexto presente, mas também sobre a responsabilidade da ciência e de cada profissional com a realidade social, cultural, econômica e política do Brasil. 
Para que o currículo possa contribuir com o processo de crítica à ideologia, o aluno deve ser estimulado a refletir. É importante que se crie o hábito de pesquisar entre os universitários. O pensamento crítico só existe com diálogo. Grupos que acreditam na educação em uma perspectiva crítica, como uma alternativa ao modelo curativo de ensino, começam a encontrar espaço dentro das universidades. São novas propostas fundamentadas em conceitos como cidadania, pedagogia crítica e metodologias ativas. As necessidades de mudança na educação em saúde e nas finalidades do trabalho em saúde são constatações generalizadas. Entretanto, é preciso reconhecer que por essas mudanças passam relações de interesse, embates políticos e disputas de poder.

Como demonstra Giroux (1986), as escolas são espaços tanto de dominação como de contestação. Embora estejam ligadas à política educacional, a interesses e recursos que carregam o peso da lógica e das instituições do capitalismo, elas também propiciam espaço para o ensino, o conhecimento e as práticas sociais emancipatórias. Segundo o autor, a ideologia, como crítica, pode ser utilizada não apenas para entender como a cultura dominante exerce o seu poder, mas também para desenvolver um modo de conhecimento que permita aos professores e alunos entender e criticar a sua prática e o mundo dos significados que relega as escolas a uma determinada relação com a sociedade dominante. Ainda para o mesmo autor, uma das formas de crítica à ideologia é atuar sobre os currículos explícito e oculto, colocando as noções de crítica e conflito no centro dos modelos pedagógicos. Nessa abordagem, a crítica deve se tornar um instrumento pedagógico vital, não apenas porque rompe com as mistificações e distorções que 'silenciosamente' operam por trás dos rótulos e rotinas das práticas, mas também porque ela propicia uma forma de resistência e de pedagogia de oposição (Giroux, 1986).

Para isso, é necessário proporcionar com o currículo um ambiente menos asséptico e mais complexo e, dessa forma, poder proporcionar ao aluno diferentes visões de mundo para que ele possa optar - a partir de uma vivência concreta no contexto histórico da sociedade e se percebendo como um ator social - pela maneira como irá atuar na construção cotidiana da realidade. Se estamos pensando na formação de profissionais de saúde com qualidades específicas para a realidade cultural e socioeconômica brasileira, é preciso reconhecer que essa tarefa é coletiva e vai além do pedagogismo reformista. Seria preciso reconhecer que:

Na produção social da própria vida, os homens contraem relações determinadas, necessárias e independentes de sua vontade. Relações de produção estas que correspondem a uma etapa determinada de desenvolvimento das suas forças produtivas materiais. A totalidade destas relações de produção forma a estrutura econômica da sociedade, a base real sobre a qual se levanta uma superestrutura jurídica e política, e à qual correspondem forças sociais determinadas de consciência. 
O modo da vida material condiciona o processo em geral da vida social, política e espiritual (Marx, 2011, p. 83-84).

Por isso mesmo é que Teixeira e Paim (1996) acreditam que vale a pena iniciar processos de reestruturação ou reforma curricular mesmo em conjunturas desfavoráveis, porém tendo em conta sempre seus limites e possibilidades. O reconhecimento de um cenário restritivo de crise econômica, social e sanitária, aliado à hegemonia política de um bloco conservador, não invalida o crescimento de um processo político participativo no interior das instituições de ensino. Segundo os autores, sinérgico à luta maior pela democratização da saúde na sociedade brasileira, esse processo político poderá ensejar o aparecimento de segmentos inovadores e novas lideranças, mesmo em instituições formadoras dominadas por grupos retrógrados. Afinal, "liderança e militância emergem da luta" (Teixeira e Paim, 1996, p. 22).

Essa mesma perspectiva de resistência e de luta também pode ser encontrada em Campos (1992), quando este autor defende a ideia de que a viabilização do SUS não pode ter como ponto central a subordinação dos trabalhadores de saúde às normas administrativas burocratizadas tradicionais que promovem um engessamento do sistema, dificultando o exercício dos recursos humanos, como um dos atores principais do processo de mudança; ou seja, não é possível fazer avançar o SUS sem a integração e o esforço dos seus trabalhadores.

Refletir sobre o modo como educação, política e ideologia se imbricam na realidade concreta dos cursos de graduação em saúde, conformando estruturas curriculares mais ou menos comprometidas com a realidade social brasileira, é um primeiro passo a ser dado nas reformas curriculares que, frequentemente, diagnosticamos como necessárias para fortalecer o sistema público de saúde e corrigir as distorções do currículo na educação superior em saúde. Para isso, há necessidade de um esforço conjunto dos profissionais de saúde nas unidades básicas e dos professores nas instituições de ensino, já que a prática profissional se torna um ponto de interseção privilegiado para se entender a natureza da sociedade atual e para a atitude necessária de formar cidadãos críticos capazes de se engajar na luta de resistência por estruturas fundamentalmente novas na organização pública da experiência.

Essa compreensão de que o campo da educação em saúde encontra-se organicamente fincado no espaço político e de que a reforma do currículo pode representar uma luta pela transformação, apesar da realidade atual, está de acordo com Paim e Almeida Filho (2000), quando afirmam que a política não é a arte do possível, mas sim a arte de construir força social capaz de mudar a realidade, tornando possível, no futuro, o que hoje parece impossível. Assim, identificar os aliados atuais e potenciais, ao mesmo tempo que se iniciam processos visando à formação de sujeitos sociais capazes de construir novas viabilidades políticas, ainda representa um dos grandes desafios. 
Compreender a educação como um processo capaz de desenvolver talentos nos sujeitos para que possam construir autonomia de escolhas - e de vida exige um currículo no qual o processo de ensino proporcione ao educando uma reflexão crítica sobre a sua prática profissional e sua responsabilidade ante a mudança ou manutenção da atual realidade social. Nesse caso, é preciso que o currículo - formal e oculto - estimule uma compreensão profunda da vida humana e da ligação que existe entre o processo de educação, a política e o processo concreto e histórico de viver. Revelada a ideologia, caberá ao estudante fazer conscientemente as suas próprias escolhas.

Entretanto, é mesmo Chauí (1994) quem alerta para o fato de que a teoria não está encarregada de 'conscientizar' os indivíduos, não está encarregada de criar a consciência verdadeira para opô-la à consciência falsa e com isso mudar o mundo. Para a autora, cabe à teoria desvendar os processos reais e históricos como resultados e como condições da prática humana em situações determinadas, prática que dá origem à existência e à conservação da dominação de uns poucos sobre todos os outros. Nesse sentido, torna-se relevante reconhecer que a práxis do homem não é a atividade prática contraposta à teoria; é a determinação da existência humana como elaboração da realidade. Assim, para Kosik (1976) a práxis compreende, além do momento laborativo, o momento existencial, portanto

[...] se manifesta tanto na atividade objetiva do homem, que transforma a natureza e marca com o seu sentido humano os materiais naturais, como na formação da subjetividade humana, na qual os momentos existenciais como angústia, a náusea, o medo, a alegria, o riso, a esperança etc... não se apresentam como 'experiência' passiva, mas como parte da luta pelo reconhecimento, isto é, do processo da realização da liberdade humana (Kosik, 1976, p. 204).

Ainda para Kosik (1976), conhecemos o mundo, as coisas e os processos somente na medida em que os (re)criamos, isto é, na medida em que os produzimos espiritualmente e intelectualmente. Entretanto, não é a teoria, mas a práxis humana fundamentada nessa teorização crítica que será responsável pelo processo de emancipação a que se refere Ricoeur (1983).

A concepção de utopia por nós utilizada procura levar em conta o caráter dinâmico da realidade, na medida em que não assume como ponto de partida 'uma realidade em si', mas antes uma realidade concreta, histórica e socialmente determinada, que se acha em constante processo de mudança. Assim como Mannheim (1982), iremos considerar utópicas somente aquelas orientações que, transcendendo a realidade, tendem a abalar, parcial ou totalmente, a ordem de coisas que prevaleça no momento.

Esse sentido de utopia, como ideal de transformação, é essencial para Mannheim (1982), quando afirma que a utopia aspira por outra realidade, 
ainda inexistente, que tem portanto uma dimensão crítica ou de negação da ordem social existente ou se orienta para sua ruptura, apresentando função subversiva e, em alguns casos, função revolucionária. Por fim, o autor afirma ainda que cada época permite surgir, em grupos sociais diversamente localizados, ideias e valores em que se acham contidas, de forma condensada, as tendências não realizadas que representam as necessidades de tal época. Esses elementos intelectuais se transformam, então, no material explosivo dos limites da ordem existente, deixando-a livre para evoluir em direção à ordem de existência seguinte.

\section{Algumas reflexões possíveis: uma análise crítica sobre a formação em saúde}

Os estudos do currículo na educação superior em saúde precisam fazer uma crítica à concepção tradicional de formação profissional que reproduz o modelo autoritário, excludente e desigual da sociedade capitalista. Historicamente, as carreiras da área da saúde são organizadas em profissões reguladas por órgãos de classe como sindicatos ou associações especializadas, que disputam o poder de dar significado aos conteúdos da formação dos profissionais de saúde e classificar a sua importância, impregnando o currículo de diversas ideologias que geralmente circunscrevem o debate da qualidade da educação superior no desenvolvimento de habilidades técnicas, omitindo a importância de abordar essa formação em uma perspectiva humanista mais abrangente.

Essa formação em uma abordagem mais humanista pode ser considerada uma vertente das teorias críticas, com o desafio adicional de que o processo de formação profissional possa efetivamente contribuir para a construção da política cotidiana nas faculdades e universidades onde se efetiva a parte mais conceitual e teórica da formação dos profissionais de saúde no Brasil. Cabe lembrar, portanto, que $70 \%$ dos profissionais de saúde no país ainda são formados em faculdades isoladas, ou seja, não estão integrados em um sistema universitário que possibilite - além da formação profissional específica - uma reflexão ética do processo de trabalho em saúde, o que significa o esforço de agir em equipe, com um coletivo de trabalho que organiza práticas de saúde contextualizadas na cultura local.

A ideologia da tecnificação da educação acabou socialmente legitimada por meio de reformas universitárias pouco democráticas, principalmente no período da ditadura militar, quando a alienação por meio da técnica seguiu sendo reproduzida historicamente como uma força de inércia e controle do pensamento. A ideologia da prática privada especializada - e também o valor do reconhecimento social pelo acúmulo de dinheiro - é mantida pela pressão que exerce o modelo de desenvolvimento do sistema capitalista. 
Se o dinheiro é o laço que me liga à vida humana, que liga a sociedade a mim, que me liga com a natureza e com o homem, não é o dinheiro o laço de todos os laços? Não é por isso mesmo também o meio geral da separação? É a verdadeira marca divisória, assim como o verdadeiro meio de união, a força, a química da sociedade (Marx, 2011, p. 76).

A justificativa da ideologia tecnicista sempre foi a necessidade de formação de mão de obra especializada para manutenção do contingente de trabalhadores que se constituem na 'reserva de mercado', sempre com o discurso de que esta é a necessidade do país para seguir em seu processo de desenvolvimento industrial e urbanização. Ou seja, um sistema produtivo que deveria se tornar a cada dia mais competitivo, fundamentado numa lógica de gestão privada instrumentalizada por tecnologias gerenciais e auditoria do desempenho de professores e alunos, fortalecendo sempre as ideias de meritocracia e performatividade duramente criticadas por Ball (1994).

Esse modelo de produção das práticas sociais fundamentado no sistema econômico capitalista recebeu ao longo da história diferentes nomes, como capitalismo industrial, capitalismo liberal, neoliberalismo, capitalismo global; mais recentemente, vem sendo denominado de capitalismo financeiro ou neoliberal. Não importa o nome com o qual se disfarça, o importante é reconhecer que os princípios desse modelo de organização do sistema produtivo promovem formas de organização espacial da sociedade com delimitação e separação de espaços nucleares centrais e territórios de periferia urbana. Nesse sentido, a própria qualidade de vida nas cidades contemporâneas depende dos níveis de distribuição ou acúmulo de riquezas que assumem características específicas em cada lugar. No Brasil, o problema não resolvido da desigualdade social e da ganância pelo acúmulo desenfreado de riquezas faz com que o poder de decisão siga nas mãos de poucos, perpetuando o coronelismo e a exploração.

Ao retornar agora ao nosso objeto de análise, é preciso reconhecer que o currículo na educação superior em saúde está circunscrito a uma realidade local concreta. Ou seja, está ligado ao cuidado de um sujeito ou do estado de saúde de uma população epidemiologicamente mapeada. Vale a pena recordar nesse momento que a responsabilidade legal pela formação profissional em saúde é principalmente do Ministério da Saúde e não só do Ministério da Educação, como ocorre com a maiorias dos outros cursos. Essa peculiaridade legal reforça e legitima a prerrogativa que têm os atores da área de saúde de regular, influenciar e direcionar a forma como as instituições de ensino superior desenvolvem seus currículos. Nesse sentido, garantir o direito à vida se sobrepõe ao direito de estudar.

O currículo formal é organizado, na maioria dos cursos de graduação em saúde, com base nas diretrizes nacionais. As diretrizes curriculares são textos que hibridizam diferentes discursos e constroem um aparato legal para o 
funcionamento do currículo e para a permanência do processo de formação do modo como é garantindo o que Bourdieu e Passeron (1975) denominaram de 'a reprodução'.

É possível que o pensamento possa estar habituado a se organizar de determinado modo e que tenha dificuldade em tornar-se permeável às mudanças. Esse habitus (Bourdieu, 1994) faz com que tenhamos a certeza de que é imprescindível trabalhar na criação de redes que possibilitem o compartilhamento intersubjetivo de uma nova linguagem elaborada no campo da comunicação interpessoal. Entretanto, o individualismo contido nos currículos e legitimado pelo sistema social e econômico que ganha a cada dia novos contornos de abrangência global favorece um silêncio estruturado sobre as relações entre classes sociais, culturas e civilizações. Mas até que ponto a formação dos profissionais de saúde é capaz de problematizar as diferenças de classe, as diferenças de cultura e os diferentes estágios de organização dos grupamentos sociais pelos quais as unidades de saúde se responsabilizam?

Ao refletir sobre as condições sociais e econômicas que determinam as políticas educacionais e constroem um determinado tipo de currículo, somos levados a pensar em algumas questões que poderiam vir a se constituir em eixos de pesquisa para os estudos das políticas públicas e do currículo no campo da educação superior em saúde:

Quais são as organizações e grupos responsáveis pela seleção dos conteúdos que compõem o currículo de um determinado curso na área da saúde? Como esse currículo se expressa realmente em diferentes instituições de ensino superior?

Ao utilizar a ferramenta metodológica do 'ciclo de políticas' proposta por Ball (1994) para se pensar o campo da educação e as políticas educacionais, qual seria o contexto de influência (conjunto de ideologias) em que se constrói o texto oficial do currículo que se materializa numa proposta curricular específica de determinada instituição de ensino superior? Qual a relação entre as instituições de ensino e as instituições ideologicamente influentes naquele determinado contexto?

Como ocorrem as negociações de significado dos discursos que são articulados e hibridizados para compor documentos e textos oficiais que conformam o currículo na educação superior em saúde? Seria possível uma proposta que articulasse diferentes discursos e intenções, ou sempre haverá o domínio de uma ideia sobre as outras?

Ao considerar que os grupos sociais não são homogêneos e nem sempre têm objetivos confluentes, como se acomodam no currículo os conflitos de interesses que surgem entre os diferentes grupos que compõem e organizam o ensino na área da saúde?

De que forma as questões de classe, gênero, raça, sexualidade e espiritualidade podem se organizar em determinadas culturas a ponto de essas abordagens 
multiculturalistas ganharem expressão na luta cotidiana que se trava pelos sentidos, pelos objetivos e pelas finalidades da educação superior em saúde?

Quais são as relações de poder que permeiam os atores envolvidos no desenvolvimento de determinada reforma curricular?

Como um currículo crítico pode ser operado na prática, e quais são os valores concretos e simbólicos sobre trabalho humano e desigualdade social que um currículo desse tipo poderia sustentar como argumentos principais?

Até que ponto o currículo na educação superior em saúde está legitimando, ou transformando, os valores de consumo alienado e a valorização dos fetiches de mercado priorizando o uso de tecnologias, equipamentos e máquinas cada vez mais caras e sofisticadas, em detrimento do diálogo e da comunicação na atenção à saúde?

\section{Considerações finais}

Ao compreender que o processo educativo é uma resultante dos instrumentos de poder e dos processos de fragmentação do conhecimento em disciplinas, então os currículos de graduação na área da saúde estariam fortalecendo o discurso hegemônico das disciplinas e legitimando processos de controle e exercício autoritário do poder, desconsiderando as necessidades, os anseios de liberdade e o potencial de criatividade dos sujeitos. Somente quando as autoridades educacionais conseguirem abrir mão de exercer autoritariamente seu poder legitimados por determinado tipo de conhecimento e buscarem compartilhar os tempo-espaços, dando voz real aos alunos como sujeitos inteligentes, é que se poderá estabelecer qualquer ambiente mais democrático e participativo nos cursos de graduação.

Conforme apontamos também ao longo deste ensaio, existe ainda, operando também e de forma menos explícita, quase como uma força subliminar, o currículo oculto, que é aquele transmitido por meio dos valores dos sujeitos envolvidos diretamente na prática do processo educativo. Nesse caso, os professores funcionam como exemplos e conformam visões de mundo que colaboram para a formação de atitudes por parte dos alunos. Desse modo, ocorre um modelamento do comportamento dos estudantes universitários por meio da regulação de seus valores principais construídos na relação cotidiana com os professores e preceptores das unidades de saúde e a inculcação de desejos próprios de cada categoria profissional.

O conceito de habitus proposto por Bourdieu (1994) é uma ferramenta teórica imprescindível para se compreender esse sistema de transmissão de valores e atitudes por meio das relações interpessoais que permeiam a cultura e determina o ambiente universitário. Portanto, quanto mais oportunidades, mais diferentes elas forem e maior a diversidade de visões de mundo que participarem da negociação dinâmica que desenvolve o currículo, mais potente 
será essa formação no sentido de estabelecer relações entre o corpo, a clínica e o cuidado. Tudo isso sem desconsiderar que essa tríade (corpo/clínica/cuidado) está inserida - e existe - num contexto determinado pela realidade econômica e social. Desse modo, o tipo de instituição (universidade ou faculdade), seu caráter social (pública ou privada) e ainda os sistemas de saúde locais (organizados na perspectiva de especialidades ou da integralidade) estão em jogo na arena em que se luta pelas definições do currículo. Assim, não podemos desconsiderar que os currículos funcionam como sistemas ideológicos que moldam subjetividades e as conformam, determinando, na maioria das vezes de forma acrítica e autoritária, a eleição de valores morais que garantem o processo de reprodução.

Mas o currículo, além de simplesmente formar profissionais para o sistema produtivo, conforma, reforma e transforma identidades e sujeitos. Se por um lado os mecanismos de identificação profissional se perpetuam por meio das associações de classe, dos conselhos profissionais e sindicatos, por outro é verdade que já existem também inúmeras forças de transformação que atuam como uma forma de resistência a essa perspectiva funcionalista.

Desse modo, redes de pesquisadores organizados em áreas de investigação, professores conscientes, alunos transgressores, famílias rebeldes e comunidades mais democráticas conseguem propor transformações para que o currículo possa ser compreendido como um processo de construção de identidades críticas e comprometidas com a realidade social, criando ambientes de formação que proporcionem ao estudante perceber distintas visões de mundo, conhecer a diversidade do pensamento humano e compreender representações, experiências e culturas.

Nessa perspectiva, cada professor é responsável pela participação política que define o tipo de currículo, mas também é responsável, junto com seus alunos, pelo processo de formação das disciplinas e das práticas de saúde em cada campo específico. Ao darem conta do currículo oculto, professores e alunos poderão tornar-se também cidadãos conscientes diante dos processos políticos que estão em disputa no currículo naquele determinado período da história.

O estímulo à transformação social pode ser também trabalhado como uma forma de construir respostas à miséria e aos processos históricos de exclusão social e pobreza que se perpetuam na sociedade brasileira. Esse compromisso social, ancorado na perspectiva da conscientização, como proposta política em Freire (1970), garantiria ao menos que as ideias tradicionais transmitidas a cada semestre nas instituições de ensino superior pudessem construir outras possibilidades de existência e desenvolver outros pontos de vista e colaborar na construção de novas esperanças, sonhos e utopias coletivas. Para isso será, portanto, necessário valorizar a cultura do aluno num entendimento de cultura como um processo social transversal à vida dos sujeitos, que depende das forças históricas em ação em determinado grupo e constrói as referências simbólicas das inumeráveis culturas que compõem o que se pode denominar de civilização humana. 
A formação crítica do profissional de saúde está intimamente relacionada ao seu potencial para contribuir com o desenvolvimento humano e social das pessoas e comunidades pelas quais é responsável - seja por meio de uma atuação técnica, seja por meio de uma ação política. Todavia, a aprendizagem de todas essas nuances só é possível por meio do diálogo. Ainda que de modo muitas vezes precário, na área da saúde esse diálogo acontece de forma muito mais eficaz do que em muitas outras áreas de formação, já que é prerrogativa mesmo da própria clínica a escuta, a ausculta e o entendimento da necessidade do outro. Portanto, é sempre possível, na área da saúde, a proposição de um modo de comunicação interpessoal que contribua para a construção do conhecimento no cotidiano da clínica. O potencial do diálogo se constrói no currículo oculto e depende da relação intersubjetiva que se dá na relação entre os sujeitos no compartilhamento sincero de suas necessidades, desejos e objetivos.

Para que essa formação possa garantir um cuidado integral, é preciso ainda aprender a se trabalhar em equipe, compreendendo que a equipe não é só um conjunto de pessoas relacionadas no processo de cuidado, mas também integrantes de outros setores de atividade em que se organizam os direitos sociais como a assistência social, a educação, a cultura, a habitação etc. O desenvolvimento de ações intersetoriais durante o processo de formação profissional é imprescindível para que se possa desenvolver competências compatíveis com o trabalho intersetorial.

A 'multi/inter/trans-disciplinaridade' só é possível na práxis por meio de um processo de construção coletiva que estimule a integração e a colaboração. Tal práxis se torna possível nos espaços curriculares de articulação ensino-serviço. Nesse espaço de interseção, o processo de trabalho em equipe permite a compreensão do sentido de ampliação da clínica, o que Campos (2003, 2005) denomina de 'clínica ampliada'. Nessa perspectiva, o cuidado deixa de ser de responsabilidade individual de um único profissional para ser exercido de modo ampliado por meio da ação conjunta de uma equipe de profissionais de saúde. Essa consciência coletiva, construída no processo de trabalho real e com base na discussão de casos cotidianos e problemas reais, também parece ser imprescindível, já que a organização dos processos de educação permanente em saúde nos serviços públicos pode colaborar para uma reflexão crítica do processo de trabalho.

Também parece ser iniciativa importante no campo da educação superior em saúde a formação dos preceptores, construindo com eles atividades educativas e modos de trabalhar os currículos que estimulem o pensamento crítico em detrimento da manutenção do autoritarismo da técnica. Nesse sentido, o potencial de revolução cultural que se desejaria nas instituições de ensino superior é funcionalmente direcionado para o imobilismo por meio de reformas curriculares que, na maioria das vezes, não significam nada além da incorporação de algumas metodologias ativas de ensino-aprendizagem ou a incorporação de novas tecnologias em velhas didáticas de ensino. 
O papel da universidade não se resume a desenvolver habilidades técnicas (apesar de ser incontestável sua importância) nos alunos. Ela também deve estimular o pensamento, a busca pelo conhecimento, a emoção e a crítica. As relações humanas não podem ser desvinculadas do seu contexto social. O currículo precisa contribuir para o desenvolvimento de atitudes de afeto e solidariedade. Começam a entrar em cena, dessa forma, todos os aspectos sociais que participam da saúde do ser humano e a compreensão de que a saúde depende das condições de vida, como trabalho, salário, moradia e lazer. As críticas ao modelo hegemônico como estão construídos os currículos já não são poucas, entretanto, a sua compreensão como território político vem de um grupo ainda restrito. As ideologias não são exclusivamente geradas na universidade, mas reproduzem um comportamento enraizado na sociedade.

Por fim, compreender a educação como um processo capaz de desenvolver os seres humanos para que possam construir autonomia de vida requer um currículo em que o processo de ensino-aprendizagem promova uma reflexão sobre a educação em saúde, assim como sobre a responsabilidade social de cada sujeito ante a manutenção, a crítica ou a transformação da realidade social. Para isso, será preciso que o currículo formal e o oculto estimulem uma compreensão profunda da vida e da cultura humana, além de um esforço de compreensão e tomada de consciência da realidade social e de como ela é reproduzida ou transformada pelas concepções de educação, política, ideologia e currículo que as forças políticas que atuam em determinada sociedade conseguirem negociar. Revelada a ideologia, caberá a cada um fazer suas próprias escolhas e, aos coletivos, trabalhar para formar novos sujeitos, ampliando o nível de consciência e formando profissionais para o SUS que trabalhem com o compromisso pela igualdade social.

\section{Colaboradores}

Gustavo de Oliveira Figueiredo concebeu os argumentos teóricos e a estrutura do ensaio, elaborou a primeira versão e fechou a versão final do texto; Yansy Aurora Delgado Orrillo contribuiu na discussão e na revisão da versão final.

\section{Financiamento}

Este suplemento "Educação e Trabalho em Saúde: diálogos e experiências no Brasil e em Portugal" foi realizado com apoio da Coordenação de Aperfeiçoamento de Pessoal de Nível Superior (Capes) - Código de Financiamento 001; e do Departamento de Pesquisa em História das Ciências e da Saúde da Casa de Oswaldo Cruz (Depes/COC/Fiocruz, 6151000000). Todos os autores declaram que não há conflito de interesses. 


\section{Agradecimentos}

Os autores agradecem as preciosas contribuições do Prof. Dr. Carlos Botazzo, da Faculdade de Saúde Pública da Universidade de São Paulo, para a elaboração da primeira versão deste ensaio.

\section{CURRICULO, POLÍTICA E IDEOLOGÍA: ESTUDIOS CRÍTICOS EN LA EDUCACIÓN SUPERIOR EN SALUD}

Resumen El objetivo de este ensayo fue analizar como las ideologías y las políticas públicas influencian en el currículo de los cursos de grado en salud. Inicialmente, se presenta la relación entre las categorías: ideología, política y currículo; centrándose en el eje de la educación superior en materia de salud, en el ámbito de la educación sanitaria. Se discute la tecnificación de la educación superior, donde los cursos de grado en salud presentan una lógica especializada, fragmentada y productivista del cuidado la salud, y cuyos currículos permiten la reproducción acrítica de la visión de mundo hegemónica durante la trayectoria de los estudiantes en la universidad. En ese camino se construyen las identidades profesionales de sujetos cuyas representaciones sociales están influenciadas por ese sistema de valores, ideas y prescripciones que penetran en la subjetividad de los educandos y educadores. Sin embargo, como el proceso educativo es dialéctico y contradictorio, la dominación no suprime la resistencia; siendo discutido en el artículo espacios de lucha contra ideológicas, bien como los retos en la construcción de un currículo que valore los saberes de los alumnos y estimule la conciencia crítica para la transformación social. Esta perspectiva permitiría la construcción de un entorno político más plural y dinámico donde se puede percibir la universidad como un espacio de formación más amplio, socialmente comprometido y coherente con las directrices del Sistema Único de Salud brasileño.

Palabras Clave política; ideología; currículo; educación superior; educación en salud.

\section{Notas}

${ }^{1}$ O Fundo Monetário Internacional desenvolve diversos instrumentos de pressão para que os países periféricos adotem um conjunto de recomendações para o desenvolvimento da política econômica. Um exemplo importante foi o documento conhecido como 'Consenso de Washington', que estabeleceu rígidas diretrizes com fórmulas neoliberais para muitos países latino-americanos. Para uma reflexão aprofundada sobre o tema, sugerimos a leitura de Tavares (1997).

${ }^{2}$ Lei n. 9.394/1996, capítulo IV, art. 53, parágrafo único, inciso III.

${ }^{3}$ Ministério da Educação, Conselho Nacional de Educação, processo n. 23001.000318/200175, parecer n. CNE/CES 1300/01, que trata das diretrizes curriculares nacionais dos cursos da área da saúde - aprovado em 6/11/2001. Disponível em: <http://portal.mec.gov.br/cne/ arquivos/pdf/CES1300.pdf > Acesso em: 10 mar, 2018.

${ }^{4}$ Subtítulo tomado emprestado de Cecília Meireles. In: MEIRELES, Cecília. Crônicas de Educação. Rio de Janeiro: Nova Fronteira, 2001. 


\section{Referências}

ALVES, Nilda; VILLARDI, Raquel. Múltiplas leituras da nova LDB: Lei de Diretrizes e Bases da Educação Nacional. Rio de Janeiro: Dunya, 1997.

BALL, Stephen J. Educational reform: a critical and post-structural approach. Buckingham: Open University, 1994.

BERLINGUER, Giovanni; GARRAFA, Volnei. A última mercadoria: a compra, venda e o aluguel de partes do corpo humano. Humanidades, Brasília, v. 8, n. 3, p. 315-327, 1993.

BOTAZZO, Carlos. Da arte dentária. São Paulo: Hucitec, Fapesp, 2000.

BOURDIEU, Pierre. A opinião pública não existe. In: THIOLLENT, Michel (org.). Crítica metodológica, investigação social e enquete operária. 5. ed. São Paulo: Polis, 1987. p. 137-151.

BOURDIEU, Pierre. Esboço de uma teoria da prática. In: ORTIZ, Renato; FERNANDES, Florestan (orgs.). Sociologia: Pierre Bourdieu. São Paulo: Ática, 1994. p. 60-61.

BOURDIEU, Pierre; PASSERON, Jean C. A reprodução: elementos para uma teoria do sistema de ensino. Rio de Janeiro: Francisco Alves, 1975.

BRASIL. Ministério da Saúde. Relatório final da $10^{a}$ Conferência Nacional de Saúde. Brasília, 2 a 6 de setembro de 1996. Brasília: Ministério da Saúde, 1998.

BRASIL. Ministério da Educação. Instituto Nacional de Estudos e Pesquisas Educacionais Anísio Teixeira (Inep). Pesquisa socioeconômica dos graduandos inscritos no provão 2000. Exame Nacional de Cursos Superiores, 2000. Disponível em: http://download.inep.gov.br/ educacao_superior/enc/2000/Dados_ENC_2000. pdf. Acesso em: 14 abr. 2018.
BRASIL. Ministério da Educação. Conselho Nacional de Educação. Parecer n. CNE/CES 1300/01, que trata das Diretrizes Curriculares Nacionais dos Cursos de Graduação em Farmácia e Odontologia. Brasília: Ministério da Educação, 2001. Disponível em: <http:// portal.mec.gov.br/cne/arquivos/pdf/CES1300. pdf>. Acesso em: 4 jun. 2017.

BRUNO, Adília M. V. Perfil do estudante de odontologia da Universidade Federal do Ceará e sua visão sobre reforma sanitária e saúde pública. 127fl. Dissertação (Mestrado em Odontologia) - Faculdade de Odontologia, Universidade Federal Fluminense, Niterói, 1994.

CAMPOS, Gastão W. S. Reforma da reforma: repensando a saúde. São Paulo: Hucitec, 1992.

CAMPOS, Gastão W. S. Saúde Paidéia. São Paulo: Hucitec, 2003.

CAMPOS, Gastão W. S. Um método para análise e cogestão de coletivos. 2. ed. São Paulo: Hucitec, 2005.

CHAUÍ, Marilena. O que é ideologia? 38. ed. São Paulo: Brasiliense, 1994.

DEMO, Pedro. Questões para a teleducação. Petrópolis: Vozes, 1998.

FIGUEIREDO, Gustavo O. Do fetichismo odontológico à utopia da saúde bucal. 100fl. Dissertação (Mestrado em Tecnologia Educacional nas Ciências da Saúde) - Núcleo de Tecnologia Educacional em Saúde, Universidade Federal do Rio de Janeiro, Rio de Janeiro, 2002.

FIGUEIREDO, Gustavo O.; BRITO, Dyla T. S.; BOTAZZO, Carlos. Ideologia, fetiche e utopia na saúde: uma análise a partir da saúde bucal. Ciência \& Saúde Coletiva, Rio de Janeiro, v. 8, n. 3, p. 753-763, 2003.

FREIRE, Paulo. Pedagogia do oprimido. Rio de Janeiro: Paz e Terra, 1970. 
FREIRE, Paulo. Pedagogia da autonomia: saberes necessários à prática educativa. 2. ed. Rio de Janeiro: Paz e Terra, 1997.

GARRAFA, Volnei; MOYSÉS, Samuel. Odontologia brasileira: tecnicamente elogiável, cientificamente discutível, socialmente caótica. Divulgação em Saúde para Debate, Rio de Janeiro, n. 13, p. 6-17, jul. 1996.

GIROUX, Henry. Teoria crítica e resistência em educação: para além das teorias de reprodução. Petrópolis: Vozes, 1986.

GRUPPI, Luciano. Conceito de hegemonia em Gramsci. Rio de Janeiro: Edições Graal, 1978.

GUIMARÃES, Regina. A articulação da psicanálise com a pedagogia crítica no ensino de psicologia médica: uma contribuição para a construção da identidade profissional. 76fl. Dissertação (Mestrado em Tecnologia Educacional nas Ciências da Saúde) - Núcleo de Tecnologia Educacional para a Saúde, Universidade Federal do Rio de Janeiro, Rio de Janeiro, 1999.

KOSIK, Karel. A 'práxis'. In: KOSIK, Karel. Dialética do concreto. 2. ed. Rio de Janeiro: Paz e Terra, 1976. p. 197-207.

LOUREIRO, Isabel. Repensando o progresso. Revista de Estudos Marxistas, São Paulo, n. 7, p. 47-63, 1999.

MANNHEIM, Karl. Ideologia e utopia. 4. ed. Rio de Janeiro: Zahar, 1982.

MARX, Karl. O capital - livro 1: o processo de produção do capital. v. 1. 2. ed. Rio de Janeiro: Civilização Brasileira, 1971.

MARX, Karl. Contribuição à crítica da economia política. 4. ed. Rio de Janeiro: Martins Fontes, 2011.

MARX, Karl; ENGELS, Friedrich. A ideologia alemã e outros escritos. Rio de Janeiro: Zahar, 1965.
MATOS, Mariângela. Sobre a formação em saúde. Jornal da Associação Brasileira de Odontologia de Promoção de Saúde, Rio de Janeiro, n. 22, ano X, p. 4, abr.-maio-jun. 2000.

MEIRELES, Cecília. Crônicas de Educação. Rio de Janeiro: Nova Fronteira, 2001.

MENDES, Durmeval. Filosofia da educação brasileira. Rio Janeiro: Civilização Brasileira, 1983.

MINAYO, Maria C. S. O conceito de representações sociais na sociologia clássica. In: GUARESCHI, Pedrinho A.; JOVCHELOVITCH, Sandra (orgs.). Textos em representações sociais. Petrópolis: Vozes, 1995. p. 89-112.

PAIM, Jairnilson S. Recursos humanos em saúde no Brasil: problemas crônicos e desafios agudos. São Paulo: USP. Coleção AdSaúde, 1994.

PAIM, Jairnilson S.; ALMEIDA FILHO, Naomar. A crise da saúde pública e a utopia da saúde coletiva. Salvador: Casa da Qualidade, 2000.

PIRES, Marilia F. Multidisciplinaridade, interdisciplinaridade e transdisciplinaridade no ensino. Interface: Comunicação, Saúde, Educação, Botucatu, v. 2, n. 2, p. 173-182, fev. 1998.

PORTILLO, Jorge A. C.; BELACIANO, Mourad I. Contribuição com vinte elementos teórico-metodológicos constituídos em função de um novo paradigma da saúde e educação. Divulgação em Saúde para Debate, Rio de Janeiro, n. 9, p. 27-32, ago. 1994.

PRETTO, Maria S. Ação e reflexão para uma prática social transformadora em saúde. 132 fl. Dissertação (Mestrado em Odontologia) - Faculdade de Odontologia, Universidade Federal Fluminense, Niterói, 1989.

QUADRA, Antonio. A. F. Relação médico-paciente: o ovo da serpente. Educação e Sociedade - Cedes, São Paulo, n. 7, p. 105-110, set. 1980.

RIBEIRO, Ana C. T. Notas sobre ideologia e educação. Interface: Comunicação, Saúde, Educação, Botucatu, v. 2, n. 3, p. 7-19, fev. 1998 
RIBEIRO, Janine. Opinião. Jornal da Associação Brasileira de Odontologia de Promoção de Saúde, Rio de Janeiro, n. 22, ano X, p. 34, dez. 2000.

RICOEUR, Paul. Interpretação e ideologias. Rio de Janeiro: Fontes Alves, 1983.

SCHRAIBER, Lilia B. Educação médica e capitalismo. São Paulo: Hucitec, Abrasco, 1989.

SEVERINO, Antonio J. Educação, ideologia e contraideologia. São Paulo: Pedagógica Universitária, 1986.

SILVA, Tomaz T. Documentos de identidade: uma introdução às teorias do currículo. Belo Horizonte: Autêntica, 1999.

SINDICATO DOS ODONTOLOGISTAS NO ESTADO DE GOIÁS (SOEGO). Entrevista com o presidente do congresso internacional de odontologia. Jornal do Soego, Goiânia, p.3, jun.-set. 2000.
TAVARES, Maria C. Da fronda ao front. Revista de Estudos Marxistas, Rio de Janeiro, n. 2, p. 5-21, jun. 1997.

TEIXEIRA, Carmen; PAIM, Jairnilson S. Políticas de formação de recursos humanos em saúde: conjuntura atual e perspectivas. Divulgação em Saúde para Debate, Rio de Janeiro, n. 12, p. 19-23, jul. 1996.

THIOLLENT, Michel. Aspectos sociais da didática universitária. Educação e Sociedade, São Paulo, v.1 n. 4, p. 123-136, 1979.

TOURAINE, Alain. Crítica da modernidade. 4. ed. Petrópolis: Vozes, 1997.

WILLIAMS, Raymond. Você é marxista, não é? Revista Praga, São Paulo, n. 2, p. 123-134, jun. 1997.

ZANETTI, Carlo H. G. Reforma do Estado e saúde. Ação Coletiva, Brasília, v. 1, n. 3, p. 15-23, 1998. 